\title{
Reflexiones sobre el ser humano en la filosofía de José Ferrater Mora
}

René Chanta ${ }^{1}$

Recibido el 3 de noviembre del 2013 y aceptado el 18 de noviembre del 2013

\begin{abstract}
Resumen.
El presente ensayo pretende aproximarse a algunas reflexiones sobre el ser humano que realizó José Ferrater Mora. Este filósofo muestra en su producción teórica una visión unitaria y global del ser humano. A la vez, realiza un diálogo con algunos representantes contemporáneos de la antropología filosófica. También, se mostrará que este pensador tenía un profundo espíritu humanista al mostrar su preocupación por el problema ecológico actual.
\end{abstract}

\section{Palabras clave:}

Ser humano, antropología filosófica, problemática antropológica, filósofo del exilio español, ecología.

\begin{abstract}
This article aims to approach some reflections José Ferrater Mora made about the human being. In his writings, this philosopher presents a global and unitary view about human beings while bringing contemporary anthropological philosophers into discussion. Besides, this article will evidence that Ferrater Mora was deeply humanist, concerned with the current ecological problems.
\end{abstract}

\section{Keywords}

Human being, philosophical anthropology, anthropological issues, philosophers in exile in Spain, ecology

\section{Introducción}

El presente trabajo tiene por objetivo mostrar de una manera general y sintética algunas reflexiones sobre el ser humano que desarrolló en su vida el filósofo español José Ferrater Mora. Conviene advertir que no se pretenderá

1 Profesor de Antropología Filosófica, en la Universidad Don Bosco.

E-mail: rene.chanta@udb.edu.sv 
en este esfuerzo académico realizar un estudio total y exhaustivo que haga referencia en forma detallada a todas las reflexiones que escribió este filósofo español sobre la realidad humana. Más bien, intentaré sistematizar sus extensos pensamientos. Esto es muy importante decirlo ya que aunque no hay una obra concreta en la producción teórica de José Ferrater Mora que se titule "antropología filosófica"; sin embargo, al hacer una exploración en las diversas publicaciones de este filósofo, es fácilmente constatable la gran cantidad de alusiones que realizó sobre temas muy significativos para la realidad humana como la muerte, la libertad, la corporalidad, etc. Para delimitar este trabajo tomo como referencia únicamente las siguientes obras: El hombre en la encrucijada ${ }^{2}$; El ser y la muerte: bosquejo de una filosofía integracionista ${ }^{3}$, Las palabras y los hombres ${ }^{4}$ y El hombre y su medio y otros ensayos. ${ }^{5}$

Realizar una clasificación filosófica de José Ferrater Mora no es una tarea fácil ya que él se movilizó en diversos ambientes académicos y literarios con variadas obras y artículos ${ }^{6}$. Sin embargo, sí se puede constatar que este filósofo español era un humanista preocupado por los problemas éticos y sociales de su tiempo. A la vez, frente a diversos reduccionismos ontológicos y antropológicos que se estaban propagando en los sectores intelectuales de la época, él propuso el integracionismo. En el integracionismo, Ferrater Mora enfatizará la necesidad de formar un puente que permita aproximarnos a diversas posturas contrarias ${ }^{7}$. Por otro lado, hay que precisar que estos escritos de Ferrater Mora sobre el ser humano están en consonancia con el gran movimiento de antropología filosófica que se inicia desde la segunda década del siglo XX con la clásica obra del filósofo alemán Max Scheller ${ }^{8}$ titulada El puesto del hombre en el $\operatorname{cosmos}^{9}$. En efecto, este libro hará que en el ámbito filosófico se produzca una amplia gama de reflexiones sobre el ser humano. Como se mostrará más

2 J. Ferrater Mora, El hombre en la encrucijada, Suramericana, Buenos Aires, 2da Edición, 1965.

$3 \mathrm{~J}$. Ferrater Mora, El ser y la muerte, bosquejo de una filosofía integracionista, Ediciones Aguilar, Madrid, 1962.

$4 \mathrm{~J}$. Ferrater Mora, Las palabras y los hombres, Editorial Península, Barcelona, 1972.

5 Ferrater Mora, El hombre y su medio y otros ensayos, Editorial Siglo XXI, Madrid, 1971.

6 Para una visión más completa de la amplia producción teórica de José Ferrater Mora puede consultarse: J. Ferrater Mora, Obras Selectas, Ediciones de la Revista de Occidente, Madrid, 1967 7 J. Ferrater Mora define en su Diccionario de Filosofía el integracionismo de esta manera: "Un tipo de filosofía que se propone tender un puente sobre el abismo con demasiada frecuencia abierto entre el pensamiento que toma como eje la existencia humana o realidades descritas por analogía con ella, y el pensamiento que toma como eje la naturaleza”. Para más información sobre el integracionismo puede consultarse su obra El ser y la muerte, bosquejo de una filosofía integracionista, sobre todo el capítulo primero.

8 Max Scheller nació en Munich en 1875. Fue docente en Jena y Munich. Se adhiere al movimiento fenomenológico. Entre sus obras destacan El formalismo en la ética y la ética material de los valores (1913) y El puesto del hombre en el cosmos (1928) en donde se muestran las principales reflexiones de Scheller sobre el ser humano. Muere repentinamente en 1928

9 M. Scheller,. El puesto del hombre en el cosmos, Editorial Losada, Buenos Aires, 1938 
adelante, ese acontecimiento hará que este pensador dialogue con diversas corrientes filosóficas que estaban circulando por los ambientes europeos y latinoamericanos.

Teniendo en cuenta lo anterior, este trabajo tendrá la siguiente estructura. En un primer momento presentaré algunos datos biográficos de este pensador junto con el contexto en el que Ferrater Mora comienza a reflexionar con más interés y constancia sobre la "problemática antropológica". Luego se procederá a ver de manera sucinta qué es antropología filosófica y cuáles son los problemas centrales sobre los cuales reflexiona esta disciplina académica. Posterior a esto, se realizará una aproximación a la metodología que utiliza el autor para reflexionar sobre el ser humano. Finalmente se hará alusión a las reflexiones que realizó Ferrater Mora para abordar el problema ecológico actual

\section{Vida y contexto de José Ferrater Mora}

Ferrater Mora nació en Barcelona en el año de 1912. Estudió la carrera de filosofía y letras en la Universidad de Barcelona bajo la dirección de Joaquin Xirau. Entre sus docentes figuraron personajes como Paul Ludwing Landsberg (discípulo de Max Scheller) y Carrera Artau. Sin embargo, Ferrater Mora siempre afirmó que la mayor parte de sus conocimientos filosóficos los aprendió por si mismo $^{10}$ convirtiéndose en un autodidacta. Su vida no fue nada fácil ya que desde finales de la década de los años treinta le tocó vivir la crueldad de la guerra civil española. Una vez finalizada la guerra y ante la derrota del bando Republicano, a Ferrater Mora le tocó vivir casi toda su vida en el exilio. De hecho, varias fuentes lo ubican dentro del grupo de filósofos del exilio español ${ }^{11}$. Esta experiencia lo llevó a vivir en diversos países como Francia, Cuba, Chile y los Estados Unidos. En este último país ejerció la docencia en Pennsylvania en el Bryn Mawr College. Fue un discípulo de Zubiri y Ortega y Gasset. Colaboró en varias revistas científicas y filosóficas. En 1987 recibe el premio Príncipe de Asturias de Comunicación y Humanidades por haber contribuido durante toda su vida a esclarecer y difundir diversas ideas filosóficas. Recibió varios doctorados Honoris Causa en universidades españolas y latinoamericanas. Finalmente, Ferrater Mora muere en su natal Barcelona en el año de 1991.

Sin duda, toda su producción teórica se vio eclipsada por su célebre obra Diccionario de Filosofía en donde se muestra una gran capacidad de síntesis

10 Cfr. "Entrevista a Ferrater Mora "en Revista El Basilisco, enero-octubre de 1981.

11 Se llaman filósofos del exilio español a un grupo de pensadores que tuvieron que abandonar España luego de la victoria de Francisco Franco en la guerra civil produciéndose así una gran diáspora cultural. Entre ellos se encuentran: María Zambrano, Xirau, Ferrater Mora. 
y conocimiento de múltiples y variadas corrientes filosóficas. En efecto, una buena cantidad de estudiantes de filosofía del ámbito hispanohablante se han enriquecido con este diccionario. Sin embargo, este autor también escribió diversas obras filosóficas y literarias en donde deja plasmada su originalidad en determinados planteamientos ${ }^{12}$. Por ejemplo, sobresale su esfuerzo por hacer una filosofía integracionista.

Como en la mayoría de pensadores, las reflexiones de Ferrater Mora no son homogéneas ni lineales sino que están marcadas por varios cambios y giros. En efecto, al acercarnos a su amplia producción podemos hallar puntos de ruptura. En ese sentido, se pueden diferenciar, a mi juicio, dos grandes etapas filosóficas en la producción teórica de Ferrater Mora ${ }^{13}$. La primera comprendería el tiempo anterior a la guerra civil española, en donde los intereses intelectuales de este filósofo catalán versaban sobre la filosofía española (especialmente Unamuno y Ortega y Gasset) y la interpretación del ser y destino de su natal Cataluña. Incluso en su principal obra en esta época, llamada Coctel de verdad (1935), no muestra mayor interés hacia los temas de la antropología filosófica. Sin embargo, a mi criterio ${ }^{14}$, el avance de la guerra civil española junto con su experiencia de exiliado van a marcar profundamente tanto su vida como su producción filosófica. Ante esto, se podría decir que a partir de sus crisis personales vividas en el exilio junto a la dura realidad del mundo circundante, sobre todo la Segunda Guerra mundial, se va a dar un cambio significativo en su producción teórica. Este cambio lo marca sobre todo su obra El sentido de la muerte $^{15}$ que fue escrita cuando estaba en Chile. Ahí se puede ver claramente un giro hacia lo antropológico-existencial. En dicho libro tratará el tema de la finitud del hombre y su estar en el mundo como realidad natural, dando así comienzo a su amplia producción antropológica con las obras: El hombre en la encrucijada, El ser y la muerte, bosquejo de una filosofía integracionista, El hombre y su medio y otros ensayos, Las palabras y los hombres, y De la materia a la razón ${ }^{16}$. En estas publicaciones, Ferrater Mora va reelaborando y actualizando su concepción sobre el hombre entrando en diálogo con muchos filósofos contemporáneos a él.

12 Cfr. O. Hora, . Un reino de este mundo: las aportaciones en ética de Ferrater Mora, en Enrahonar, número 44, 2010, págs. 35-49.

13 Los datos que expongo son limitados, ya que a 22 años de su muerte, no hay un estudio sistemático que dé cuenta de los intereses filosóficos de Ferrater Mora durante su exilio. Como fuentes se pueden mencionar ciertas entrevistas que realizó Ferrater y el sitio http://www. filosofia.org/rev/ bas/bas22134.htm

14 Cfr. http://www. filosofia.org/rev/bas/bas22134.htm

$15 \mathrm{~J}$. Ferrater Mora, El sentido de la muerte, Editorial Suramericana, 1947.

16 J. Ferrater Mora, De la materia a la razón, Alianza Editorial, 1983. 
En síntesis, lo importante de este apartado es vislumbrar la posibilidad de que el ambiente contextual va ser un factor determinante y desencadenante para que su producción filosófica se oriente hacia los temas antropológicos. En mi opinión creo también que a lo anterior hay que sumar el contacto que Ferrater Mora tuvo con las obras de algunos filósofos de la Escuela de Madrid y de otros pensadores que estaban exiliados como José Gaos, García Bacca, etc. En ese sentido considero que las lecturas de los libros de Xavier Zubiri van a influir bastante para que sus concepciones sobre el ser humano se afiancen y consoliden $^{17}$.

\section{Antropología filosófica: El ser humano como un ser complejo y problemático}

Como es sabido, la antropología filosófica es un esfuerzo teórico por abordar al ser humano desde una perspectiva unitaria y sistemática y que cobra un importante auge sobretodo desde 1928 con la obra de Max Scheler El Puesto del hombre en el Cosmos. De acuerdo a Scheller ${ }^{18}$, ninguna época de la historia había experimentado al ser humano tan problemático como en la actualidad. Por otra parte, dirá también que a pesar de que hoy en día poseemos muchos datos sobre el ser humano, todavía no hay una ciencia que aborde de manera unitaria a la realidad humana. Nos dice Scheller:

Tras una historia de ya más de diez mil años, estamos en una época en que, por primera vez, el hombre es para si mismo un ser radical y universalmente problemático. El hombre ya no sabe quién es y se da cuenta de que jamás lo llegará a saber. Solo se volverá a tener juicios fundamentados si se hace tabula rasa de todas las tradiciones relacionadas con este problema y se contempla con el máximo rigor metodológico y con el más grande estupor a ese ser llamado hombre ${ }^{19}$

A la luz de todo lo anterior, podemos ver que la antropología filosófica es una disciplina reciente en el campo de la filosofía lo cual no quiere decir que no hayan existido reflexiones sobre el ser humano antes de la obra de Scheller. En efecto, ideas y reflexiones sobre el hombre se han dado desde los inicios de la humanidad. Como muestra de eso se pueden mencionar las obras de los sofistas,

17 Diversas obras de Zubiri aparecen citadas en las obras de Ferrater Mora al tratar la realidad humana. Entre esas obras a las que hace referencia en sus publicaciones se pueden mencionar: $E l$ problema del hombre, Naturaleza, historia , Dios (1944), En torno al problema de Dios (1935-1936) 18 De acuerdo a Carlos Beorlegui casi todos los que reflexionan sobre antropología filosófica ven a Max Scheller como el pionero en replantearse nuevamente "el problema del hombre". Sin embargo, este autor prefiere hablar de la Escuela de Scheller para referirse a Gehlen, Scheller y Plessner. Para más detalle consultar Beorlegui, Antropología Filosófica, Nosotros urdimbre solidaria y responsable, Universidad de Deusto, 1999.

19 M. Scheller, El puesto del hombre en el cosmos, Barcelona, 2000. 
los griegos clásicos y de la gran mayoría de los pensadores del renacimiento ${ }^{20}$. Sin embargo, desde la obra de Scheller se puede considerar que la antropología filosófica es la rama de la filosofía que estudiará profundamente "el problema del hombre". El problema del hombre es interrogarse profundamente sobre ¿Qué es el ser humano? y darse cuenta que el ser humano es un ser complejo que no se agota en una definición. A la vez, a esa pregunta central sobre el ser humano habría que sumarle otras interrogantes vitales e interconectadas como ¿Cuál es el sentido de la existencia del hombre? ¿De dónde viene el ser humano? ¿Existe vida después de la muerte? ${ }^{21}$.

A este nuevo replanteamiento sobre la realidad humana es a lo que contemporáneamente podríamos denominar "antropología filosófica" y a la vez nos permite diferenciar a esta disciplina de la antropología científica. A criterio de Ferrater Mora, la antropología científica coincide con la antropología filosófica en preocuparse constantemente acerca del ser humano. Sin embargo, la antropología científica se ocupa del ser humano en cuanto ser psicofísico y su pregunta central sería ¿Cuál es el lugar del ser humano dentro de la naturaleza? Por su parte, la antropología filosófica sin ignorar que el ser humano es un ser natural, extiende su campo de estudio y se plantea como cuestión fundamental cual es el puesto y el destino del ser humano en el universo ${ }^{22}$.

Sin duda, el siglo XX nos ha dado grandes pensadores que continuaron profundizando en la realidad humana desde la óptica de la antropología filosófica. Entre estos pensadores se pueden mencionar: Plessner, Gehlen, Martin Buber, Erich Rothacker, y Xavier Zubiri²3.

Por otro lado, un tema de suma importancia en antropología filosófica es dilucidar cuál es la diferencia particular y específica que tiene el ser humano con respecto a otros seres. En este punto, de acuerdo a varios pensadores, el ser humano es el único que se cuestiona sobre si mismo y que por eso es un ser trascendente. Nos dice Jaime Vélez:

Fuera del hombre, otros seres no se cuestionan sobre su propio ser, debido a que carecen de autoconciencia, y así son incapaces de

20 Pico Della Mirandola, Discurso sobre la dignidad del hombre, Colección Pequeños y grandes ensayos, UNAM, México, 2003

21 Cfr. J. Gevaert, El problema del hombre, introducción a la antropología filosófica, Decimotercera edición, Sígueme, Salamanca, 2003, págs. 10-24.

22 Para esta sección es muy sugerente consultar la voz "Antropología” en el Diccionario de filosofía de J. Ferrater Mora. En este caso se consultó la segunda reimpresión de la quinta edición aparecida en 1971 en la Editorial Suramericana, Buenos Aires.

23 C. Beorlegui, op. Cit, pág. 334. 
preguntarse sobre su propio ser. En los animales la presencia en si mismos o conciencia sensible, por ser inconsciente (no refleja), es ajena a cualquier problematicidad [...]. En cambio, al preguntarse por su propia esencia, el hombre trasciende la inmediatez de su realidad dada en su conciencia; por lo mismo busca el fundamento o razón de ser de su realidad, es decir, indaga quién es él, o sea, cuál es su esencia ${ }^{24}$.

En esa misma línea, Scheller dedica un capítulo de su obra para hablar sobre la diferencia entre los animales y el ser humano. De acuerdo a Scheller esta diferencia no está en la inteligencia o en la facultad de elegir sino que se encuentra en "el espíritu". En ese aspecto, Scheller afirma que el ser humano, con "el espíritu", ya no está atado a sus impulsos o al mundo circundante sino que es un ser libre y abierto al mundo.

\section{La metodología usada por Ferrater Mora para aproximarse a la problemática antropológica}

Una vez visto cuáles son los temas fundamentales que se plantea la antropología filosófica conviene aproximarnos a la metodología que utiliza Ferrater Mora para reflexionar sobre el ser humano. En su producción teórica, Ferrater Mora nunca define lo que es antropología filosófica incluso ni siquiera la menciona de manera directa. En base a lo anterior hay que aclarar que lo que el autor entiende por antropología filosófica hay que entresacarlo e imaginarlo a posteriori, es decir, luego de leer y comprender sus escritos entorno al ser humano. Para comprender esto, hay que ver la metodología que Ferrater Mora usa al reflexionar sobre el ser humano. Para esto utilizaré la obra Las palabras y los hombres.

a) En primer lugar, Ferrater Mora hace una especie de balance histórico y afirma que hay que hacer memoria y constatar que en la historia de la humanidad se han dado múltiples definiciones del hombre. Se ha dicho, por ejemplo que el hombre es un ser racional, creación de Dios, homo sapiens, homo faber, homo loquax, homo universalis, etc. Nos dice Ferrater Mora:

No hay escasez de ideas sobre el hombre y su puesto en el cosmos. Cada cultura, cada época, cada religión, casi cada sistema filosófico posee, o ha poseído, sus propias ideas acerca de la condición humana. 
Los hombres se han consagrado con frecuencia a meditar sobre lo que son y más a menudo sobre lo que no son"25.

b) En segundo lugar, el autor hace un ejercicio de crítica y quiere constatar que ninguna de esas definiciones aciertan a la hora de definir lo que realmente es el ser humano. Por ejemplo, dirá que es impropio llamar al hombre homo universalis, es decir, el considerar que el ser humano no tiene domicilio fijo y ha poblado todo el planeta, ya que si nos vamos a los hechos del pasado, los dinosaurios también fueron capaces de poblar todo el planeta tierra siendo auténticamente universales. El otro caso es la definición de homo faber, es decir, el considerar que el ser humano es el único animal que produce herramientas y tecnología. Dirá que la ciencia actual demuestra que determinadas especies de primates como los chimpancés usan piedras para abrir sus semillas o palos para ciertas actividades cotidianas. Así, aunque en un nivel muy primitivo, estos animales están usando herramientas también. Por tanto, ninguna de estas dos definiciones nos dicen exactamente lo que es el hombre. $Y$ de esa forma el autor va criticando cada afirmación como "homo erectus", "animal racional", "homo loquax ${ }^{26 ", ~ e t c, ~ p a r a ~ m o s t r a r ~ q u e ~ n i n g u n a ~ f o ́ r m u l a ~ d e f i n e ~ e n ~ s u ~ t o t a l i d a d ~}$ lo que el hombre es.

c) Por último dirá que la razón por la cual él ha afirmado que ninguna de estas definiciones aciertan al definir al ser humano, es porque quiere persuadir a algunos lectores que hoy en día, todavía se puede proponer otra imagen del hombre.

Nos dice:

“El único modo de seguir conservando estas fórmulas [...] es refinarlas en varios de los sentidos antes sugeridos, pero entonces dejan de ser las fórmulas que pretendían ser y se convierten en cosa distinta: en puntos de partida para un análisis antropológico-filosófico ${ }^{27}$.

De esta manera, se puede concluir que por más definiciones que se construyan sobre el ser humano, ninguna logra englobarlo en su totalidad. Ferrater Mora está en estrecha relación con muchos filósofos que afirman que hay que despojarse de las antiguas definiciones acerca del hombre para hacer una auténtica antropología filosófica ya que en definitiva esas definiciones dejan puntos sin resolver y lo que se debe hacer es una revisión a fondo de la forma en

$25 \mathrm{~J}$. Ferrater Mora Las palabras y los hombres, página 20.

26 Homo loquax, es decir, hombre hablante, que produce lenguaje.

27 J. Ferrater Mora, José, “Las palabras y los hombres”, página 27. 
cómo pensamos al ser humano. El mismo afirma que esas fórmulas (ser racional, homo loquax, homo sapiens, etc) no deben ser absolutizaciones sino que hay que relativizarlas, refinarlas y convertirlas no en punto de llegada sino en punto de partida de una auténtica reflexión antropológico-filosófica. Al decir punto de partida, está enfatizando que a pesar de haberse escrito mucho sobre el hombre en el pasado, no nos sentimos satisfechos. No estamos en la meta sino que nos hallamos todavía en el banderín de salida en la reflexión sobre el hombre.

También hay que puntualizar que el autor se halla en sintonía con muchos de los autores que recientemente han escrito sobre antropología filosófica y por eso considero que Ferrater Mora quiere dar una imagen distinta del ser humano ante el agotamiento de la fórmulas y definiciones anteriores. Eso se va a concretar en el siguiente apartado en donde se trata la concepción de hombre que tiene este filósofo del exilio español.

\section{TEORIA DEL HOMBRE}

Aquí Ferrater Mora quiere proponer una teoría del hombre en sintonía con lo que se ha elaborado últimamente en antropología filosófica. Dirá que en estos tiempos para entender al hombre no debemos volver a los dualismos que fragmentan, limitan, empobrecen y deforman al ser humano. Más bien, de acuerdo a este filósofo español hay que afirmar que el hombre es una unidad. Lo anterior, no quiere decir que Ferrater Mora se oriente hacia una visión monista que niegue la trascendencia humana. Una vez afirmado esto dirá que el problema está en ¿Cómo entender esa unidad llamada vida humana?28

En primer lugar Ferrater Mora destacará la corporalidad del hombre, diciendo que el ser humano es sobretodo un cuerpo. Aquí coincidirá con Max Scheller al decir que el hombre es una entidad biológica, que se halla compuesta de elementos pertenecientes a la naturaleza inorgánica ${ }^{29}$. Incluso dirá que en el ser humano hay elementos fundamentales de la realidad entera. Entonces, el ser humano es un microcosmos. Pero ahí mismo va incluida la novedad del ser humano ya que el hombre es un microcosmos que en lugar de reflejar pasivamente el macrocosmos (como lo hacen los otros seres vivientes), se vierte hacia él por medio de la conciencia. El hombre por tanto puede conocer en dos direcciones: conoce el mundo y se conoce a así mismo, destacándose así la primera diferencia con los otros seres vivientes.

28 Cfr., J. Ferrater Mora, "El sentido de la muerte”, páginas 157-158

29 En efecto, Scheller afirma que:"El puesto singular del hombre nos aparece claro cuando dirigimos nuestra atención a la estructura total del mundo biopsiquico", M. Scheller, op cit, pág. 27. 
Luego, citando a Zubiri nos dice que la diferencia esencial entre el hombre y los demás seres vivos es que los seres vivientes están solo viviendo mientras que el hombre está haciendo la vida ${ }^{30}$. A esto él lo llama la diferencia entre la vida biológica y la vida humana. Ahí entrará a analizar el tema de las relaciones del hombre con su medio. Dirá (siempre siguiendo a Zubiri) que los seres vivos se relacionan con su medio de una manera enclasada de acuerdo a su especie biológica y eso es fundamentalmente el estar viviendo. En cambio, hacer su propia vida es romper con ese círculo cerrado de su especie y poder inventar y proponer modos de vida capaces de transformar la especie. Para explicitar mejor esto dirá que cada especie posee su mundo y el comportamiento del ser viviente corresponde con la estructura de tal mundo y ahí hay una pertenencia total del ser viviente individual al de su especie. No hacen su vida, sino parte de la vida de la especie a la cual pertenecen. En el hombre eso no ocurre ya que el ser humano no está viviendo como el resto de animales sino que él hace su propia vida. El hombre se va a relacionar con el mundo en cuanto realidad objetiva independiente de sus necesidades biológicas y a veces en contra de ellas ${ }^{31}$.

Luego Ferrater Mora va a aceptar que lo propio de los seres humanos es el "espíritu" o "la persona”, entendiendo esto como la capacidad que tiene el ser humano para entrar en sí mismo, es decir, de volver en sí. Pero afirma que eso hay que hacerlo con dos condiciones. Primero, que no se designe con la idea de espíritu algo absolutamente trascendente al ser humano, y menos algo opuesto a lo material. Segundo, que no se vea al espíritu como algo que en alguna medida "ya es" sino algo procesual que se va haciendo. Esto está en consonancia con las visiones antropológicas que enfatizan que el ser humano es dinámico y abierto. Diciéndonos en este caso que el hombre se forma, se espiritualiza, se personaliza. Es decir, a lo largo de su vida se va personalizando (espiritualizando) ya que tal espíritu no puede concebirse sino es existiendo y para que exista tiene que pasarle cosas, en definitiva, ser histórico ${ }^{32}$. En base a ello también dirá que el hombre no es que tenga libertad sino que el hombre a lo largo de su vida se va haciendo libre. Nos dice: "La libertad no le es dada, se la hace. Mejor: se la va haciendo a medida que libremente se constituye"3".

Otro de los temas humanos que más ocupo a Ferrater Mora es el de la muerte, con lo cual toca la problemática de la finitud del hombre. Para ello también

30 Cfr. J. Ferrater Mora, "El ser y la muerte", capítulo III, teoría del hombre y la muerte humana, páginas 161-165. Ediciones Aguilar, Madrid, 1962.

31 Cfr. J. Ferrater Mora, El ser y la muerte, op cit, pág. 162-163.

32 Cfr. Ibid, págs. 170-172.

33 Ibid, página 185. 
analiza las formas de cesación de lo inmaterial y de los seres orgánicos. La muerte será un problema plenamente humano. ¿Por qué? Lo inorgánico cesa, la materia deja de estar integrada en una determinada estructura para formar parte de otros sistemas. Los animales orgánicos cesan también, pero lo que ocurre en el ser humano, es que él es el único que tiene conciencia de su muerte, y su muerte puede afectar toda la existencia humana. El hombre sabe que se encamina a la muerte ante la experiencia de la muerte de los otros y al mismo tiempo reflexiona sobre la muerte cosa que no hacen los otros seres. El hombre es el único ser que se ha planteado la cuestión de la supervivencia. De ahí que conviene hablar de la muerte como problema auténticamente humano. ¿Por qué? Nuevamente, el hombre es el único que puede entrar en sí o mejor dicho que va entrando en sí a lo largo de su vida. Aquí tiene continuidad con Scheller que habla de una certeza espontánea e innata de la muerte.

Sintetizando el pensamiento del autor en torno al hombre se puede decir que la vida humana no es algo acabado como las otras especies. El hombre necesita hacer su vida y está abierto a muchas posibilidades. Esto no lo tienen los otros seres por estar enclasados en su medio.

Finalmente, un tema que preocupó mucho a Ferrater Mora son las posturas extremas y excluyentes que pueden hacer mucho daño a una concepción del hombre. Él llama a estos extremos el naturalismo a la manera aristotélica que considera que el hombre es parte de la naturaleza y no puede salirse de ese círculo sin ninguna posibilidad de cambio y, la otra postura sería la existencialista o circunstancialista que considera que el hombre es solo historia y que no posee naturaleza. Ambas posturas le parecen al autor exageradas y absolutistas, que dificultan una correcta comprensión del ser humano. Uno de esos extremos es que el hombre es algo fijo y no puede cambiar. La otra postura, por su parte afirma que somos maleabilidad infinita ${ }^{34}$. Ferrater querrá superar ambas posturas. Nos dice:

La realidad humana concreta es la que oscila de continuo entre tales polos; el hombre no es nunca ni pura circunstancialidad ni elemento puramente invariable; rebota de continuo de uno al otro para constituirse [...] no es ni pura historia ni pura naturaleza, es en cierto modo ambas ${ }^{35}$

34 Cfr. "El ser y la muerte: bosquejo de una filosofía integracionista, páginas 186-189.

$35 \mathrm{~J}$. Ferrater Mora, "El ser y la muerte: bosquejo de una filosofía integracionista", páginas 187188 


\section{El ser humano ante el problema ecológico}

Como hemos visto en las líneas anteriores, de acuerdo a Ferrater Mora el ser humano no está viviendo sino que hace su vida y está abierto a diversas opciones y posibilidades incluso a dejar de ser sí mismo. En este punto se podría decir que el ser humano es la única entidad ética. Por dicho motivo el autor también se interesa por el tema de la ética del hombre analizando su sociedad y sus crisis. Ferrater se plantea cuatro preguntas que resumen su forma de problematizar al ser humano ante las crisis sociales actuales:

“¿Puede el progreso material acompañarse de un progreso espiritual o moral?, ¿Puede confiarse en el hombre y en su capacidad de renovación? ¿O es el hombre una pura bestia y su historia llena de insensateces y crueldades? ¿Está el futuro ya cerrado y concluido y nos encontramos en un callejón sin salida?"36

Concretamente, Ferrater Mora analiza el problema de la técnica, el de la organización de la sociedad junto con la destrucción ecológica. La cuestión de fondo en esos problemas según el autor es la salvación del individuo. Afirmará que el problema ecológico va cada vez de mal en peor puesto que al medio ambiente se explota con una gran tecnología y puede llevar a una ecocatastrofe y la consecuente desaparición del ser humano ${ }^{37}$. En ese sentido, el autor va a formular la necesidad de una renovación del hombre aunque Ferrater Mora no dice en qué propiamente debe consistir dicha renovación. Lo que si dará son algunas pistas para realizar esa renovación.

A criterio de Ferrater Mora se tendrá que hacer de la persona un fin sin por ello divinizarla. A la vez se tendrá que mantener la organización de la sociedad sin destruir la libertad de las personas como lo hacen los fascismos. Finalmente enfatiza la necesidad de fomentar la técnica sin matar el espíritu humano ni cosificar a los hombres ${ }^{38}$. Con esto puede verse la preocupación humanista de Ferrater Mora que no lleve a los impersonalismos o a realizar reduccionismos antropológicos que minusvaloran la imagen del ser humano.

En cuanto al problema ecológico dirá que es importante cuidar nuestro planeta ya que es nuestra madre y nos dio la vida. Plantea que parte de esa renovación debe ser que el hombre debe dejar a lo demás el derecho a existir también. Nos dice:

36 Ferrater Mora, Obras completas, El hombre en la encrucijada, páginas 543-546.

$37 \mathrm{Cfr}$. J. Ferrater, El hombre y su medio y otros ensayos, páginas 15-22.

38 Cfr. J. Ferrater, Obras completas, el hombre en la encrucijada, páginas 567-568. 
Un tipo enteramente nuevo de sociedad es una verdadera revolución cultura, y para que ésta tenga sentido ha de consistir, en una dimensión esencial, en reconocer que no sólo el hombre tienen derecho a existir [.... ] su existencia y estabilidad están ligadas a la existencia y estabilidad de muy complejos sistemas ecológicos [...] el hombre no es moralmente viable a menos de permitir que lo no humano -la tierra, el aire, el agua, el fuego y las innumerables especies animales y vegetales- exista y prospere. Vivir consiste asimismo en convivir y dejar vivir ${ }^{39}$

Aquí vemos la preocupación ética del autor ante el deterioro ecológico y a pesar de que el hombre tiene muchas posibilidades y puede hacer muchas cosas, no todas son moralmente viables so pena de desaparecer junto con las otras especies. En esto hay concordancia con los ecologistas actuales que advierten sobre la contaminación y el calentamiento global que puede llegar a afectar la calidad de vida de las personas en el futuro.

\section{Reflexiones finales.}

Luego de este breve recorrido por algunas ideas que expresó Ferrater Mora sobre la realidad humana, se puede ver que este filósofo da una imagen integral del ser humano ajeno a posturas dualistas o reduccionistas. A continuación a manera de resumen de lo que se ha expresado en las líneas anteriores resaltaré algunos puntos relevantes de su antropología filosófica.

1. Tiene una actitud crítica ante el gran cúmulo de definiciones que se han dado para comprender al ser humano. Muchas de esas fórmulas ya están agotadas y es necesario ir por otro camino para comprender lo que es el hombre.

2. En segundo lugar Ferrater Mora está en diálogo con la ciencia biológica al afirmar que el hombre es un cuerpo y la corporalidad es la fuente de donde brotan los actos humanos.

3. Por otro lado coincide con Scheller al decir que lo específico del ser humano es "el espíritu" entendido este como la capacidad de volver en sí mismo. El espíritu no es algo inmaterial ni algo estático. Más bien, el ser humano continuamente se va espiritualizando a lo largo de su vida cuando vuelve en sí. 
4. Otro tema en el que coincide con Scheller es en el tema de la muerte. Scheller afirmaba que el ser humano tiene una certeza de muerte, es decir, él sabe que va a morir. Ferrater Mora también aceptará eso aunque lo complementará un poco más. Dice que el hombre sabe que va a la muerte y esa certeza de muerte configura el sentido de su vida. Así, el hombre es la única entidad que profundiza sobre el tema de la muerte e incluso ha imaginado formas específicas de supervivencia. En efecto, el imaginar vida luego de la muerte es un hecho verificable en múltiples culturas. No importa la forma bajo la cual se conciba la supervivencia humana (alma inmortal, cielo, reencarnación). Lo relevante para el tema antropológico es que el hombre siempre ha soñado e imaginado con ser inmortal.

\section{Referencias.}

Beorlegui Carlos,. Antropología Filosófica, Nosotros urdimbre solidaria y responsable, Universidad de Deusto, 1999.

Ferrater Mora, José,. El hombre en la encrucijada, Suramericana, Buenos Aires, 2da Edición, 1965.

Ferater Mora, José,. Diccionario de filosofía, Quinta Edición, Editorial Suramericana, 1971

Ferrater Mora, José,. El sentido de la muerte, Editorial Suramericana, 1947.

Ferrater Mora, José,. De la materia a la razón, Alianza Editorial, 1983.

Ferrater Mora, José,. El ser y la muerte, bosquejo de una filosofía integracionista, Ediciones Aguilar, Madrid, 1962.

Ferrater Mora, José, . Las palabras y los hombres, Editorial Península, Barcelona, 1972.

Ferrater Mora, José,. El hombre y su medio y otros ensayos, Editorial Siglo XXI, Madrid, 1971.

Ferrater Mora, José,. Obras Selectas, Ediciones de la Revista de Occidente, Madrid, 1967

Gevaert, Joseph,. El problema del hombre, introducción a la antropología filosófica, Decimotercera edición, Sígueme, Salamanca, 2003.

Scheller M, El puesto del hombre en el cosmos, Editorial Losada, Buenos Aires, 1938.

Revista El Basilisco,. “Entrevista a Ferrater Mora”, enero-octubre de 1981.

Hora, Oscar, Un reino de este mundo: las aportaciones en ética de Ferrater Mora, en Enrahonar, número 44

Vélez Correa, Jaime,. El hombre un enigma, Colección de textos básicos para seminarios latinoamericanos, Publicaciones CELAM, Bogotá, Colombia, 2001. 